\title{
Continuous monitoring of the boundary-layer top with lidar
}

\author{
H. Baars, A. Ansmann, R. Engelmann, and D. Althausen \\ Leibniz Institute for Tropospheric Research, Leipzig, Germany \\ Received: 10 April 2008 - Published in Atmos. Chem. Phys. Discuss.: 5 June 2008 \\ Revised: 16 October 2008 - Accepted: 22 October 2008 - Published: 10 December 2008
}

\begin{abstract}
Continuous lidar observations of the top height of the boundary layer (BL top) have been performed at Leipzig $\left(51.3^{\circ} \mathrm{N}, 12.4^{\circ} \mathrm{E}\right)$, Germany, since August 2005. The results of measurements taken with a compact, automated Raman lidar over a one-year period (February 2006 to January 2007) are presented. Main goals of the study are (a) to demonstrate that BL top monitoring with lidar throughout the year is possible, (b) to present the required data analysis method that permits an automated, robust retrieval of BL top at all weather situations, and (c) to use this opportunity to compare the lidar-derived BL top data with respective BL tops hourly predicted by the regional weather forecast model COSMO. Four different lidar methods for the determination of the BL top are discussed. The wavelet covariance algorithm is modified so that an automated retrieval of BL depths from lidar data is possible. Three case studies of simultaneous observations with the Raman lidar, a vertical-wind Doppler lidar, and accompanying radiosonde profiling of temperature and humidity are presented to compare the potential and the limits of the four lidar techniques. The statistical analysis of the one-year data set reveals that the seasonal mean of the daytime (about 08:00-20:00 Local Time, LT) maximum BL top is $1400 \mathrm{~m}$ in spring, $1800 \mathrm{~m}$ in summer, $1200 \mathrm{~m}$ in autumn, and $800 \mathrm{~m}$ in winter at the continental, central European site. BL top typically increases by $100-300 \mathrm{~m}$ per hour in the morning of convective days. The comparison between the lidar-derived BL top heights and the predictions of COSMO yields a general underestimation of the BL top by about $20 \%$ by the model.
\end{abstract}

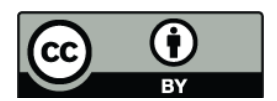

Correspondence to: H. Baars

(baars@tropos.de)

\section{Introduction}

The boundary layer (BL) is directly influenced by the Earth's surface and responds to surface forcing by frictional drag, evaporation and transpiration, and sensible heat transfer with a timescale of an hour or less (Stull, 1988). Vertical fluxes of latent and sensible heat throughout the BL have thus a strong impact on local and regional weather. Regarding air quality, the BL height determines the volume available for pollutant dispersion and the resulting concentrations and is therefore one of the fundamental parameters in many dispersion models. Continuous observation of the BL top with high vertical and temporal resolution is thus desirable to support weather and air-quality prediction.

The top of the BL can be determined in several ways (Beyrich, 1997; Cohn and Angevine, 2000; Seibert et al., 2000; Emeis et al., 2004; Wiegner et al., 2006). Active remote sensing of meteorological parameters, trace gases, and aerosols by means of sodar, radio acoustic sounding system, wind profiler, ceilometer, and lidar appears to be most appropriate for a continuous BL top detection. All of these instruments, however, have their restrictions regarding weather conditions, spatial and temporal resolution, measurement range, and accuracy.

Lidar permits the detection of the BL top with a vertical resolution of a few meters and a temporal resolution in the range of seconds to minutes. Lidar has no limitation regarding measurement range. Even the highest BL tops of 3$4 \mathrm{~km}$ in Europe or 4-6 km over the Sahara can be detected. Aerosol is used as tracer. The only limitation arises from light attenuating water clouds with optical depth $>2$. In the presence of a cumulus cloud deck, the BL top cannot be detected. But in any case of broken cloud fields as it is usually the case during convectively active days, lidars will always be able to detect the BL top. 
It has been criticized that unattended, continuous operation of a lidar is not possible because of security reasons, and that lidar is not able to detect rather low BL tops. This is no longer true. By using a small radar the laser beam can be blocked whenever an aircraft appears in a well-defined cone above the lidar site. Accurate alignment of the lidar (laserbeam receiver field-of-view), the potential to measure several signals simultaneously, and the fact that a lidar can easily be equipped with a near-range and a far-range telescope, guarantees high-quality BL top detection even at heights lower than $100 \mathrm{~m}$ if this is a requirement. Furthermore, in recent years several efforts have been undertaken to develop the software for an automated analysis of lidar data, e.g., regarding aerosol/cloud discrimination, aerosol layer identification, and for an automated retrieval of aerosol backscatter and extinction profiles (Campbell et al., 2002; Turner et al., 2002; Liu et al., 2004; Morille et al., 2007; Althausen et al., 2008).

Several lidar techniques for BL top detection have been suggested (Russel et al., 1974; Hooper and Eloranta, 1986; Piironen and Eloranta, 1995; Flamant et al., 1997; Menut et al., 1999; Steyn et al., 1999; Cohn and Angevine, 2000; Brooks, 2003). The ideas behind the methods are described in Sect. 3. Latest applications, comparisons and discussions of these methods can be found in Lammert and Bösenberg (2005), Martucci et al. (2007), and Morille et al. (2007). We contribute to this discussion by comparing the available methods for different aerosol and meteorological conditions. Primary goal of the study is however to demonstrate that a reliable, automated lidar monitoring of the BL top throughout the year, i.e., during all seasons is possible. We improved the wavelet analysis technique (Brooks, 2003) which is well suited for such a task by introducing modifications that permit a robust analysis of a long-term data set, in our case of a one-year data set (February 2006-January 2007). In the case studies presented, Doppler lidar observation of the height profile of the vertical-wind component and radiosonde measurements of pressure, temperature, and relative humidity were performed in addition. The Doppler lidar monitors the diurnal cycle of convective activity (upward and downward motions) with high vertical and temporal resolution and precisely indicates the beginning of the evolution of the BL in the morning and of the formation of the residual layer in the late afternoon and thus the collapse of the daytime BL. We use the opportunity of the lidar monitoring to compare the observed BL-top data set with model-derived BL top heights. The employed weather prediction model COSMO (Consortium for Small-scale Modelling) is a regional scale weather forecast model of the German Meteorological Service and provides BL heights on a hourly basis.

The paper is organized as follows. The compact Raman lidar is described in Sect. 2. The lidar-based BL top detection methods are briefly explained in Sect. 3. In addition, the COSMO model approach of BL identification is described. In Sect. 4, the modified wavelet covariance technique is outlined. The observations (case studies) are dis- cussed in Sect. 5. Section 6 presents the main findings of the statistical analysis of all lidar measurements taken from February 2006 to January 2007. The results are compared with respective COSMO predictions. A short summary and concluding remarks are given in Sect. 7.

\section{Instrumentation}

\subsection{Polly}

The small and compact Raman lidar Polly (POrtabLe Lidar sYstem, Althausen et al., 2004) was employed for the study. The setup is shown in Fig. 1a together with a photo of the automated lidar (Fig. 1b). A frequency doubled Nd:YAG laser (BigSky model CFR200) is used as the light source. It emits pulses of $120 \mathrm{~mJ}$ at $532 \mathrm{~nm}$ wavelength with a repetition rate of $15 \mathrm{~Hz}$. The light beam is expanded by a factor of 8 which reduces the divergence of the outgoing beam to less than $0.5 \mathrm{mrad}$. Two mirrors are used to transmit the light into the atmosphere and to keep the light beam as close as possible to the line-of-sight of the receiver telescope.

The backscattered light is collected with a Newtonian telescope which has a primary mirror diameter of $20 \mathrm{~cm}$ and a focal length of $80 \mathrm{~cm}$. The receiver field of view is set to $1.25 \mathrm{mrad}$. After separating and passing the respective interference filters, the photons elastically backscattered at 532-nm wavelength and the photons inelastically (Raman) scattered by nitrogen molecules at $607 \mathrm{~nm}$ are detected with photomultipliers (PMT, Hamamatsu, type R5600P). All signals are amplified and acquired by a photon counter. The bin width of the data acquisition card (Fast ComTec, model 7882 ) is $250 \mathrm{~ns}$ which results in a spatial resolution of $37.5 \mathrm{~m}$. The maximum (reliable) count rate of the PMT-preamplifier unit is about $10 \mathrm{MHz}$.

The incomplete laser-beam receiver-field-of-view (L-R) overlap (Wandinger and Ansmann, 2002) restricts the observational range for the detection of layer boundaries to heights above $200 \mathrm{~m}$. The L-R overlap is complete at $500-800 \mathrm{~m}$. In our study we use the elastically backscattered $532 \mathrm{~nm}$ lidar return signal for BL top detection. We concentrate on daytime BL developments. Detailed studies of the nighttime BL would require changes in the lidar configuration to obtain a complete L-R overlap at much lower height and a data acquisition unit that allows signal recording with $7.5 \mathrm{~m}$ height resolution.

To avoid large data gaps (several weeks) in our one-year time series caused by potential laser damages we decided to perform $\mathrm{BL}$ observations from minute 8-13 of each hour only (during routine observations). The case studies in Sect. 5 however are based on continuous lidar observations throughout the day (without interruptions) .

It is worth noting that Polly can provide much more information of the lower troposphere than just the BL top height. This small aerosol Raman lidar allows us to measure height 
profiles of the volume extinction coefficient profile of the particles at $532 \mathrm{~nm}$, to estimate the respective particle optical depth, and to determine the extinction-to-backscatter ratio (lidar ratio) at nighttime (Ansmann et al., 1992; Ansmann and Müller, 2005). The lidar ratio is useful in the characterization of the aerosol type (Müller et al., 2007). By using a narrow interference filter (with a spectral width of $0.2 \mathrm{~nm}$ instead of $2 \mathrm{~nm}$ as used here) in front of the nitrogen Raman channel, aerosol extinction profiling in the BL is possible even at daytime.

Polly was moved to China in 2004 to characterize the optical properties of aerosols over the heavily polluted Pearl River Delta in southern China in the autumn of 2004 (Ansmann et al., 2005; Müller et al., 2006) and over Beijing in January 2005 (Tesche et al., 2007). In the last two years we developed a Polly ${ }^{X T}$ (extended version; Althausen et al., 2008) which has seven receiver channels for backscatter profiling at 355, 532, and $1064 \mathrm{~nm}$ and extinction profiling at 355 and $532 \mathrm{~nm}$, and to measure the depolarization ratio at $355 \mathrm{~nm}$.

\subsection{WiLi}

During days with pronounced BL evolutions discussed below, radiosondes were launched and the Doppler wind lidar WiLi for vertical-wind observations was operated in addition. The Doppler lidar emits laser pulses of $1.5 \mathrm{~mJ}$ at $2022.5 \mathrm{~nm}$ wavelength. The repetition rate is $750 \mathrm{~Hz}$. Measurements are made with a resolution of $75 \mathrm{~m}$ and 5-30 s. The heterodyne detection scheme allows us to measure lineof-sight wind speeds in the BL up to $20 \mathrm{~m} / \mathrm{s}$ with a resolution of about $0.1 \mathrm{~m} / \mathrm{s}$. Further details are given in Zeromskis et al. (2003) and Engelmann et al. (2008). Lowest measurement height is $400 \mathrm{~m}$.

\subsection{Radiosonde}

2-3 Vaisala RS-80 radiosondes were launched at the lidar site per day during the observations presented in Sect. 5 (case studies). The radiosondes provide geopotential height, temperature $\vartheta\left({ }^{\circ} \mathrm{C}\right)$, and relative humidity $\mathrm{RH}$ at the pressure levels. From these quantities, the water-vapor-to-dry-air mixing ratio and the virtual potential temperature are calculated.

\section{Methodology}

\subsection{Lidar}

A variety of lidar techniques have been developed to identify the BL top. The best candidates are the gradient method (Flamant et al., 1997; Menut et al., 1999), the variance analysis (Piironen and Eloranta, 1995; Menut et al., 1999), and the wavelet covariance technique (Cohn and Angevine, 2000; Brooks, 2003). The gradient and the wavelet covariance a)
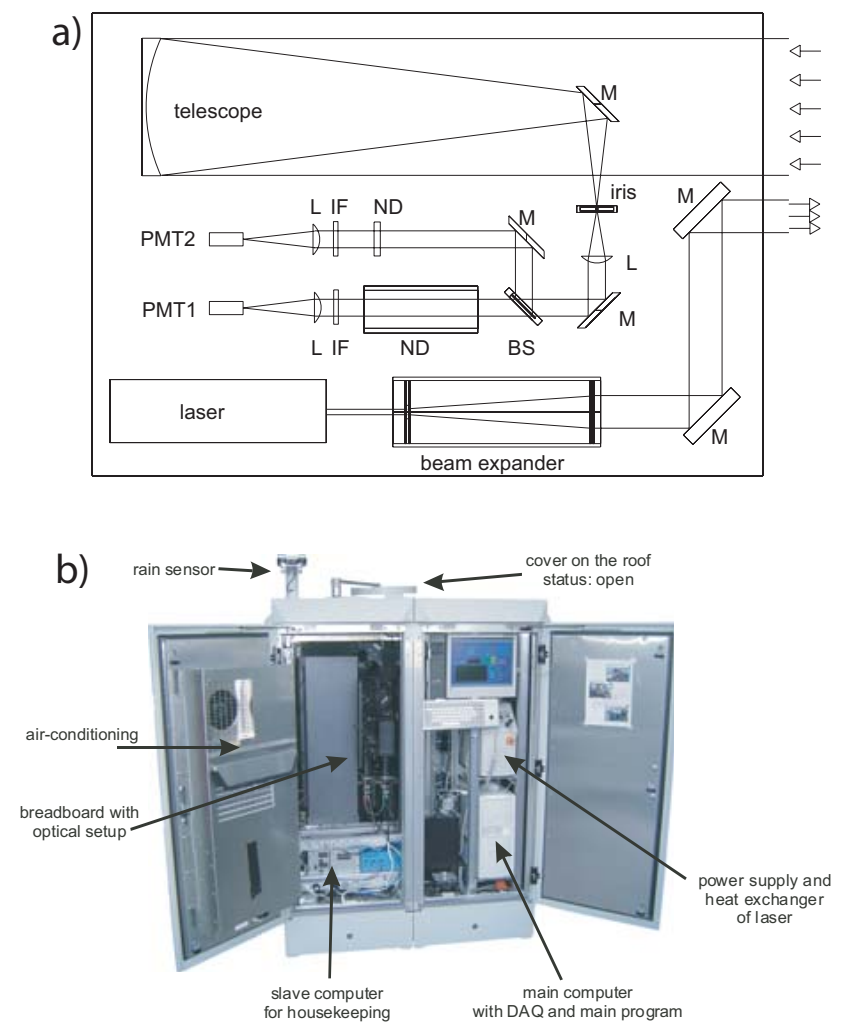

Fig. 1. (a) Schematic optical septup of Polly, M-mirror, Llens, PMT-photomultiplier tube, ND-neutral density filter, BSbeamsplitter, and IF-interference filter, (b) photograph of the Polly cabinet (1.8 $\mathrm{m}$ high).

methods assume that the BL contains much more aerosol particles than the free troposphere so that a strong decrease of the backscatter signal is observable at BL top. The variance analysis technique makes use of the strong temporal variation of the lidar signal at BL top caused by entrainment of clear air from the free troposphere into the BL.

The gradient method and the variance analysis approach are illustrated in Fig. 2a and b, respectively. The substance in Fig. 2a is assumed to be the concentration of atmospheric aerosol particles, but could also be the water vapor mixing ratio. In the case of particles, the corresponding lidar signal (after overlap, background and range-correction) is similar to the profile shown in Fig. 2a.

In the gradient method, the first (or second) derivative of the corrected lidar signal with respect to height is used (Flamant et al., 1997; Menut et al., 1999). The minimum gradient indicates the BL top. Similarly, the variance analysis (Hooper and Eloranta, 1986; Piironen and Eloranta, 1995; Menut et al., 1999) searches for a maximum in the profile of the sum of the squares of the lidar signal deviations from the mean value of, e.g., a five-minute or 1-h measurement period (see Fig. 2c). The maximum is reached in the center 
$\begin{array}{lllll}-4 & -2 & 0 & 2 & 4\end{array}$

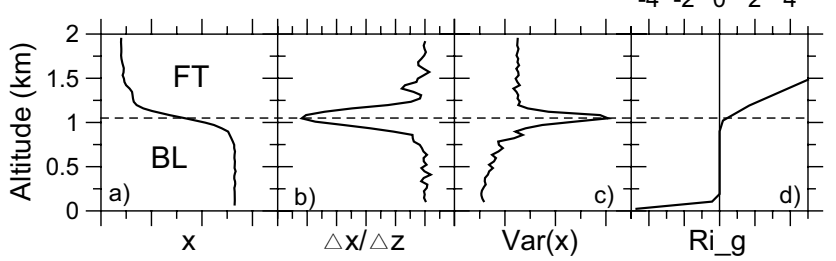

Fig. 2. (a) Idealized profile of an atmospheric quantity $x$ (e.g., particle concentration) that shows rather different values in the boundary layer BL and in the free troposphere (FT), (b) the corresponding profile of the vertical gradient of $x$, and (c) the profile of the variance $\operatorname{Var}(x)$ computed from successively measured profiles of $x(z, t)$. $\operatorname{Var}(x)$ is typically largest at BL top because of entrainment of FT air into the BL. (d) Profile of the gradient Richardson number $R i_{-} g$ for a well-mixed, convective BL (as indicated in (a)) with stable stratification in the FT.

of the transition zone. The transition zone (or entrainment layer) is defined as the layer in which mixing of polluted boundary-layer and clean free-troposphere air significantly influence the aerosol concentration at any height within this layer. The third method is the wavelet covariance transform (WCT) method. This technique is described in detail in Sect. 4 and illustrated in Fig. 3.

In the fourth lidar approach (Steyn et al., 1999), the BL top height is determined just by fitting an idealized backscatter profile to the measured one shown in Fig. 2a. The idealized profile is characterized by height-independent backscattering in the lower BL, a smooth decrease of the backscatter signal in the transition zone, and again height-independent backscattering in the free troposphere. According to this method the top of the BL coincides with the center of the transition zone. The idealized function is defined by four parameters, namely the mean backscatter coefficients in the $\mathrm{BL}$ and in the free troposphere, and the center height (BL top height) and vertical depth of the transition zone. The fit algorithm searches for the optimum solution (best fit).

Figure $2 \mathrm{~d}$ shows how the BL top is obtained from the gradient Richardson number $R i_{-} g$. This approach is explained in the next subsection.

\subsection{BL top from COSMO model}

The non-hydrostatic numerical weather prediction (NWP) model COSMO was developed at the German Meteorological Service (DWD) as a flexible tool for operational NWPs on the meso- $\beta(5-50 \mathrm{~km})$ and meso- $\gamma$ scale (50$500 \mathrm{~km}$ ) (Fay and Neunhäuserer, 2006). The COSMO model used here is operational at the DWD with a horizontal resolution of $7 \mathrm{~km}$ and 35 vertical layers since the end of 1999. Documentation is provided at the COSMO web site (http://www.cosmo-model.org).
The operational gradient-Richardson-number scheme is based on the diagnostic version of the turbulence parameterisation scheme of COSMO and applied to determine the height of the BL top. The method searches for the transition from the dynamically and thermally unstable BL to the stable layer above the BL. A critical Richardson number (0.38 in the COSMO model) is introduced to identify the top of the BL. The Richardson number is lower than 0.38 in the turbulent BL and exceeds the critical value when turbulence production significantly weakens and finally vanishes at the top of the BL. This is illustrated in Fig. 2d.

An extended discussion of the critical-Richardson-number approach is given by Zilitinkevich and Baklanov (2002). The method is unable to describe a boundary layer in stable stratification that may extend from heights close to the surface to altitudes above $3 \mathrm{~km}$. Such conditions are often given during nighttime. The method implies that the boundary layer is in a steady state. Thus, only the equilibrium BL top can be provided rather than the actual BL height (Zilitinkevich and Baklanov, 2002). The limits of the Richardsonnumber approach are further discussed by Vogelezang and Holtslag (1996) and Steeneveld et al. (2007) and alternative approaches to predict the boundary layer are suggested.

The critical Richardson number of 0.38 was retrieved from extended comparisons of COSMO- and radiosonde-derived BL tops in a wide variety of synoptic situations (Fay et al., 1997). COSMO provides forecasts two times per day for $48 \mathrm{~h}$. BL top heights are computed for each full hour. The model is initialized at 00:00 and 12:00 UTC. To obtain the height at which the gradient Richardson number exactly assumes the value of 0.38 an interpolation between two model layers is made which leads to an interpolated height.

Based on validation campaigns it has been found that the BL top height is systematically underestimated by approximately $10 \%$ to $20 \%$. During convective situations or periods with frontal passages an underestimation of $30 \%$ has been observed (Fay, 1998). Episodes of strong inversions in winter may often not allow the computation of the BL top height. Nighttime values were found to be usually not reliable. The nighttime standard value for Leipzig (rather flat terrain) is set to $389 \mathrm{~m}$.

The minimum BL top height is $200 \mathrm{~m}$ in the model. If lower values are computed, e.g., in cold winter nights, these values are replaced by a BL top height of $200 \mathrm{~m}$. If no BL top is found below $3000 \mathrm{~m}$ or if the atmosphere is non-turbulent at all, a default value of about $1200 \mathrm{~m}$ for Leipzig is computed.

In this paper, BL tops derived from 00:00 and 12:00-UTC analysis data and the corresponding 1- to 11-h forecasts are used. We focus on daytime measurements when the BL top height is usually well defined and located at heights clearly above $500 \mathrm{~m}$. 

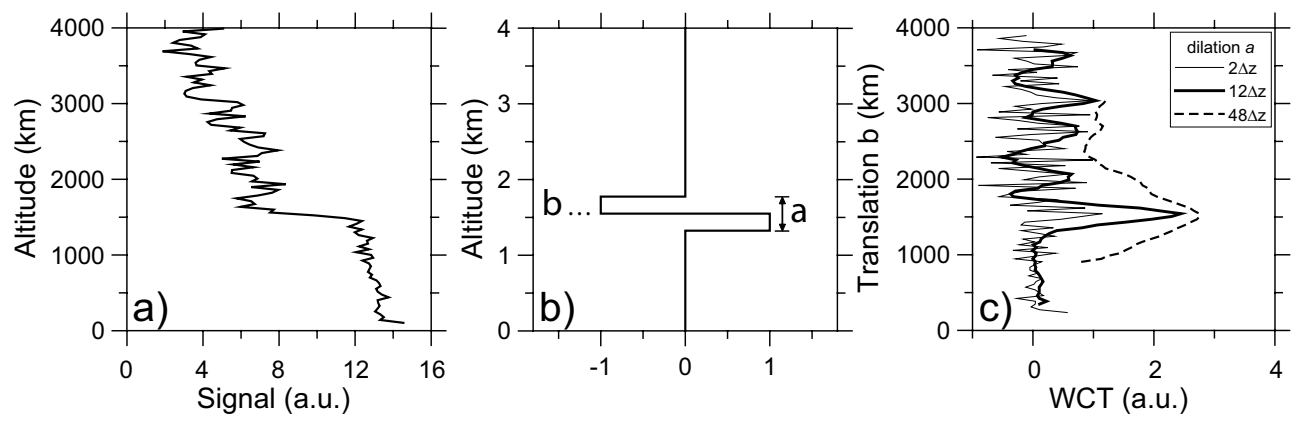

Fig. 3. (a) Lidar signal profile (range-corrected signal in arbitrary units, a.u.), (b) Haar function for the spatial extent or dilation $a=12 \Delta z$ and the height $b=1.5 \mathrm{~km}$ at which the Haar function is centered (the translation of the Haar function), and (c) resulting covariance transform at values of $a=2 \Delta z, 12 \Delta z$, and $48 \Delta z$, corresponding to 75,450 , and $1800 \mathrm{~m}$ for the lidar vertical resolution of $\Delta z=37.5 \mathrm{~m}$, respectively.

\section{Wavelet covariance transform}

The operation of a fully automated BL lidar includes an automated data analysis. This in turn implies that a robust method is available that can handle very different weather and aerosol situations during all seasons of the year. We selected the wavelet covariance transform (WCT) method for this task. The WCT technique basically analyzes the aerosol signatures of the range-corrected signal profile and is less affected by signal noise than the gradient and variance methods, that analyze the vertical signal gradients and the fast temporal changes in the signal time series as a function of height. Several thresholds (modifications to the WCT technique) however are required to guarantee a successful data analysis throughout the year. The WCT technique is described in Sect. 4.1. The modifications are presented in Sects. 4.2-4.4.

\subsection{Method}

The WCT is defined as (Brooks, 2003)

$W_{f}(a, b)=\frac{1}{a} \int_{z_{b}}^{z_{t}} f(z) h\left(\frac{z-b}{a}\right) \mathrm{d} z$

with the Haar function

$h\left(\frac{z-b}{a}\right)= \begin{cases}+1, & b-\frac{a}{2} \leq z \leq b, \\ -1, & b \leq z \leq b+\frac{a}{2}, \\ 0, & \text { elsewhere }\end{cases}$

$f(z)$ in Eq. (1) is the range-corrected lidar backscatter signal $P(z) z^{2} . z$ is the measurement height, $z_{b}$ and $z_{t}$ are the lower and upper limits of the lidar return signal profile, respectively. A Polly lidar signal profile $P(z) z^{2}$ is shown in Fig. 3a. The step function $h\left(\frac{z-b}{a}\right)$ is illustrated in Fig. 3b. The dilation $a$ is the extent of the step function. The translation $b$ determines the location of the step.
The covariance transform $W_{f}(a, b)$ is a measure of the similarity of the range-corrected lidar backscatter signal and the Haar function. In the case of a clear lidar profile signature as in Fig. 3a with high backscatter values in the BL and significantly lower backscatter values in the free troposphere, $W_{f}(a, b)$ takes a clear local maximum at the height of the BL top provided an appropriate value of $a=n \Delta z$ is chosen, as is the case for $n=12$ in Fig. 3c. The height resolution $\Delta z$ is $37.5 \mathrm{~m}$ in the case of Polly.

The selection of an appropriate value of the dilation $a$ is the main challenge for a successful retrieval of the BL top height with the WCT method. For rather small values of $a$, signal noise dominates the vertical profile of $W_{f}$ (see Fig. 3c for $a=2 \Delta z=75 \mathrm{~m}$ ). On the other hand, a too large dilation may not permit us to resolve the BL top when further aerosol layers are present in the lower free troposphere. The optimum value for $a$ is equal to the depth of the transition zone (Brooks, 2003), which is usually not known.

Three constraints are introduced in the following to guarantee a robust data analysis. The first threshold is needed to decide whether the determined BL top height is reliable or not. Section 4.2 discusses this problem. The problem that signals get increasingly noisy with height so that aerosol layer identification gets worse and worse with height is tackled in Sect. 4.3. Finally, data records affected by strongly light-attenuating clouds must be identified. Cloud segment identification by means of the WCT is explained in Sect. 4.4.

\subsection{Threshold value of the WCT}

A threshold value for the WCT is introduced that allows us to identify a significant gradient and to omit the weak gradients. According to Eqs. (1) and (2) and with $f(z)=P(z) z^{2}$, the discretized form of the WCT can be written as 

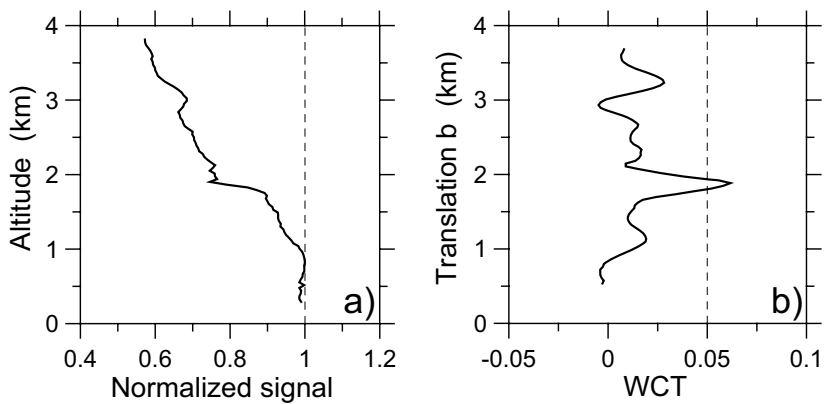

Fig. 4. (a) Normalized range-corrected lidar signal and (b) resulting covariance transform as a function of translation $b$ at dilation $a=12 \Delta z$ (450 m). The WCT threshold value of 0.05 is used to clearly identify the BL top.

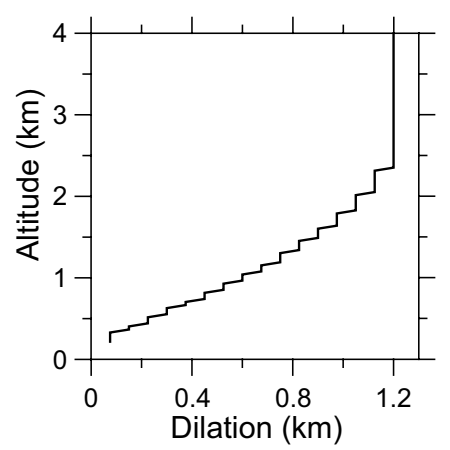

Fig. 5. Height-dependent dilation $a$ as used in the one-year data analysis. A quadratic increase with height is shown.

$$
\begin{aligned}
W_{f}(a, b) & =\frac{1}{n \Delta z}\left(\sum_{b-\frac{a}{2}}^{b} P(z) z^{2} \Delta z-\sum_{b}^{b+\frac{a}{2}} P(z) z^{2} \Delta z\right) \\
& =\frac{1}{n}\left(\sum_{b-\frac{a}{2}}^{b} P(z) z^{2}-\sum_{b}^{b+\frac{a}{2}} P(z) z^{2}\right) .
\end{aligned}
$$

The dilation is given by

$a=n \Delta z, n=2,4,6,8, \ldots$,

and the position of the translation $b$ has to be chosen in between two discrete data points to assure an equal number of data points in each integral.

According to Eq. (3), $W_{f}(a, b)$ can thus be simply expressed by the mean range-corrected signal values below and above the height of translation $b$ for layers of thickness $a / 2$. In the next step, we normalize the range-corrected signal by its maximum value found below $1000 \mathrm{~m}$. This is usually the maximum value of $P(z) z^{2}$ within the BL. The normalization guarantees the applicability of the threshold method at
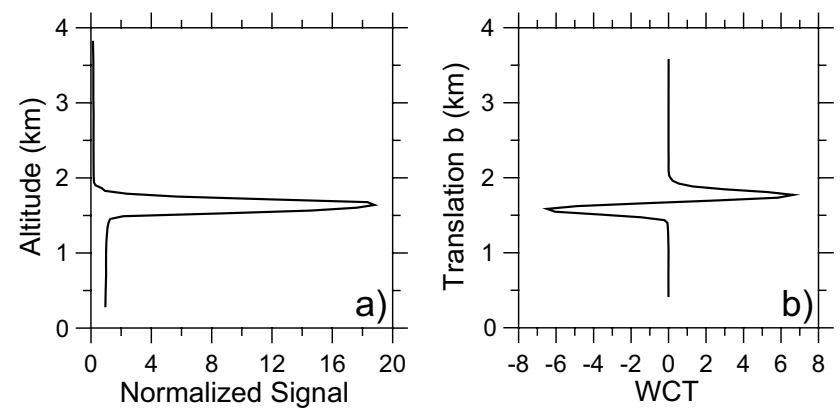

Fig. 6. (a) Normalized range-corrected lidar signal and (b) resulting covariance transform as a function of translation $b$ at dilation $a=6 \Delta z(225 \mathrm{~m})$. The specific WCT profile feature can be used to identify cloud layers.

very different backscatter conditions in rather clean or very polluted air. An example of a normalized signal and the corresponding WCT is presented in Fig. 4. $W_{f}(a, b)$ takes a clear local maximum with a value of 0.06 for the translation $b=b_{\max }=1900 \mathrm{~m}$ (height of the BL top). A value of 0.06 corresponds to a decrease of the mean signal by about 15$20 \%$ at BL top. By analyzing the entire one-year lidar data set with different threshold values from $0.02-0.15$, the value of 0.05 was found to be sufficient to identify the BL depth. Values $<0.04$ often led to temporally unreasonable fluctuating BL depths, and for values $>0.08$, many BL tops were not detected. The first height above ground at which a local maximum of $W_{f}(a, b)$ occurs, that exceeds the threshold value of 0.05 is defined as the BL top height $z_{i}$. If the threshold condition is not fulfilled, a BL top is not provided by the algorithm.

As mentioned above, we concentrate on the determination of the height of the daytime BL top. If nighttime BL observations (e.g., from 17:00-18:00 UTC to 07:00-08:00 UTC) are of interest, another approach must be developed and another (smaller) threshold value must be defined to properly identify the BL height close to the ground. A more appropriate L-R overlap profile should be used (see Sect. 2.1), and the lidar vertical resolution should be $10 \mathrm{~m}$ or better.

\subsection{Height-dependent dilation}

As described above, the choice of a proper dilation $a$ is important. The selection of a fixed dilation $a=12 \Delta z$ works well except for cases with very shallow BL or very extended transition zones. Our experience shows that the use of a dilation profile $a(z)$ described by a quadratic increase of the dilation with height (see Fig. 5) is a good compromise to detect very low BL top heights with usually very narrow transition zones, but also the extended transition zones (usually observed at heights above $500-1000 \mathrm{~m}$ ). 

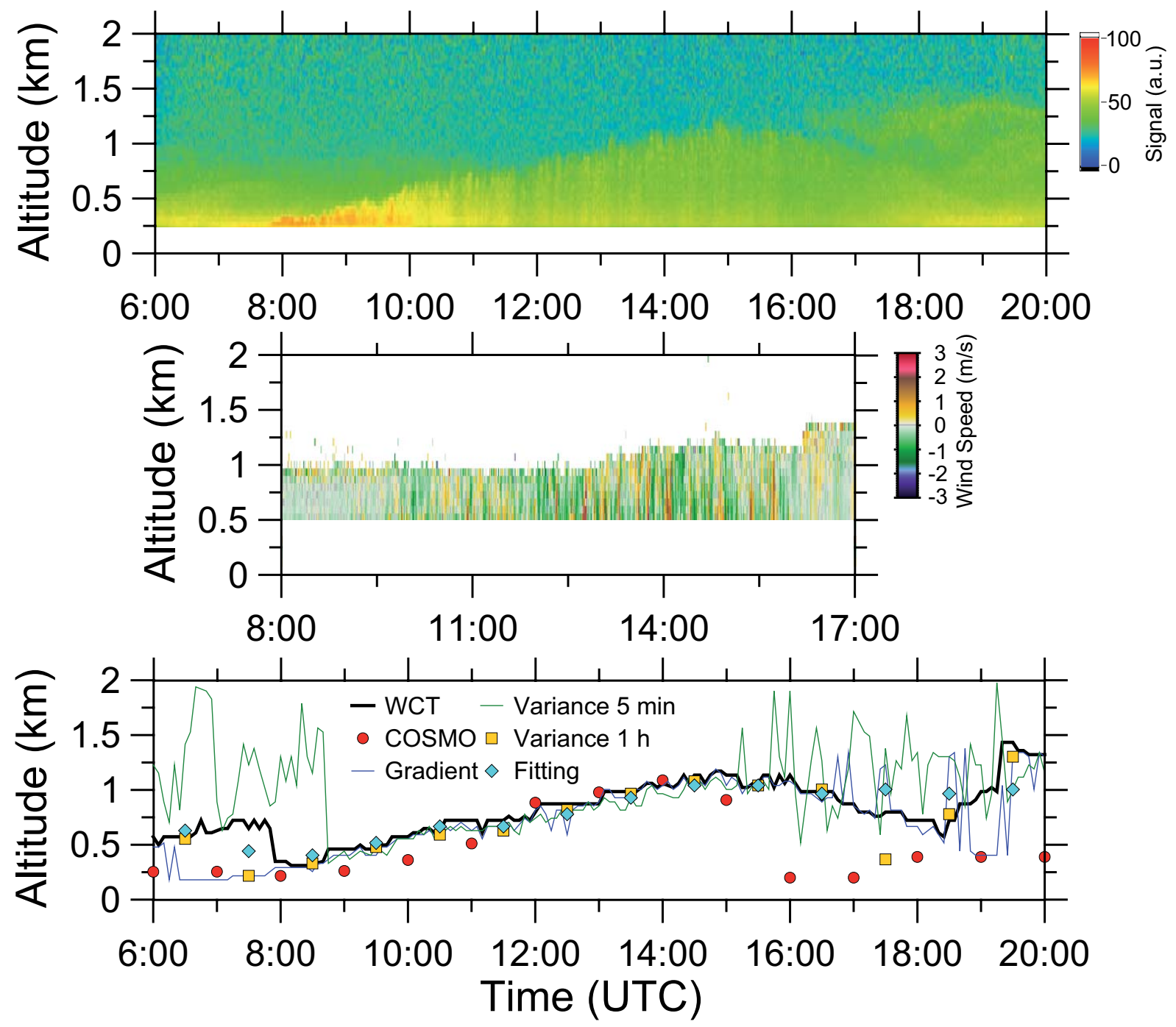

Fig. 7. Evolution of the BL at cloudfree conditions observed with backscatter lidar Polly (top, range-corrected 532-nm signal, $30 \mathrm{~s}, 37.5 \mathrm{~m}$ resolution) and Doppler lidar WiLi (center, vertical wind, 30 s, 75 m resolution) on 11 September 2006, 06:00-20:00 UTC (07:00-21:00 LT, Central European Time). Minimum measurement heights are 200 and $500 \mathrm{~m}$ for Polly and WiLi, respectively. BL top heights (bottom) are determined from the Polly observations by applying the WCT, gradient, variance, and fitting methods. Five-minute signal averaging is applied in the case of the WCT and gradient methods, 1-h signal averaging in the case of the fitting method. Solutions of the 5-min and 1-h variance analysis are obtained from the set of 30-s signal profiles measured within 5 minutes and $1 \mathrm{~h}$, respectively. BL top heights derived from the COSMO model are shown in addition (red circles).

\subsection{Cloud screening}

Clouds are characterized by a steep increase of the rangecorrected lidar signal at the cloud base followed by a strong decrease of the signal with increasing cloud penetration depth. In Fig. 6a such a cloud signal with cloud base at about $1400 \mathrm{~m}$ is presented. The WCT is shown in Fig. 6b. Due to the definition of the Haar function, $W_{f}(a, b)$ has a characteristic shape. It becomes negative at the cloud base and shows a local minimum before it becomes positive with a local maximum. Thus, the cloud can be identified by means of a negative threshold. It was found that cloud detection works very well for a threshold of -0.1 and for a dilation of $a=6 \Delta z=225 \mathrm{~m}$. The cloud base is then one height bin below the altitude at which $W_{f}(a, b)$ is lower than the chosen threshold value. In Fig. 6, cloud base is at $1397 \mathrm{~m}$.

If a cloud is detected in the lidar profile, only values below the cloud base are used for the determination of the BL top. If no significant gradient can be detected, it is very probable that this cloud has formed within the BL. In that case, no BL top height is provided. 

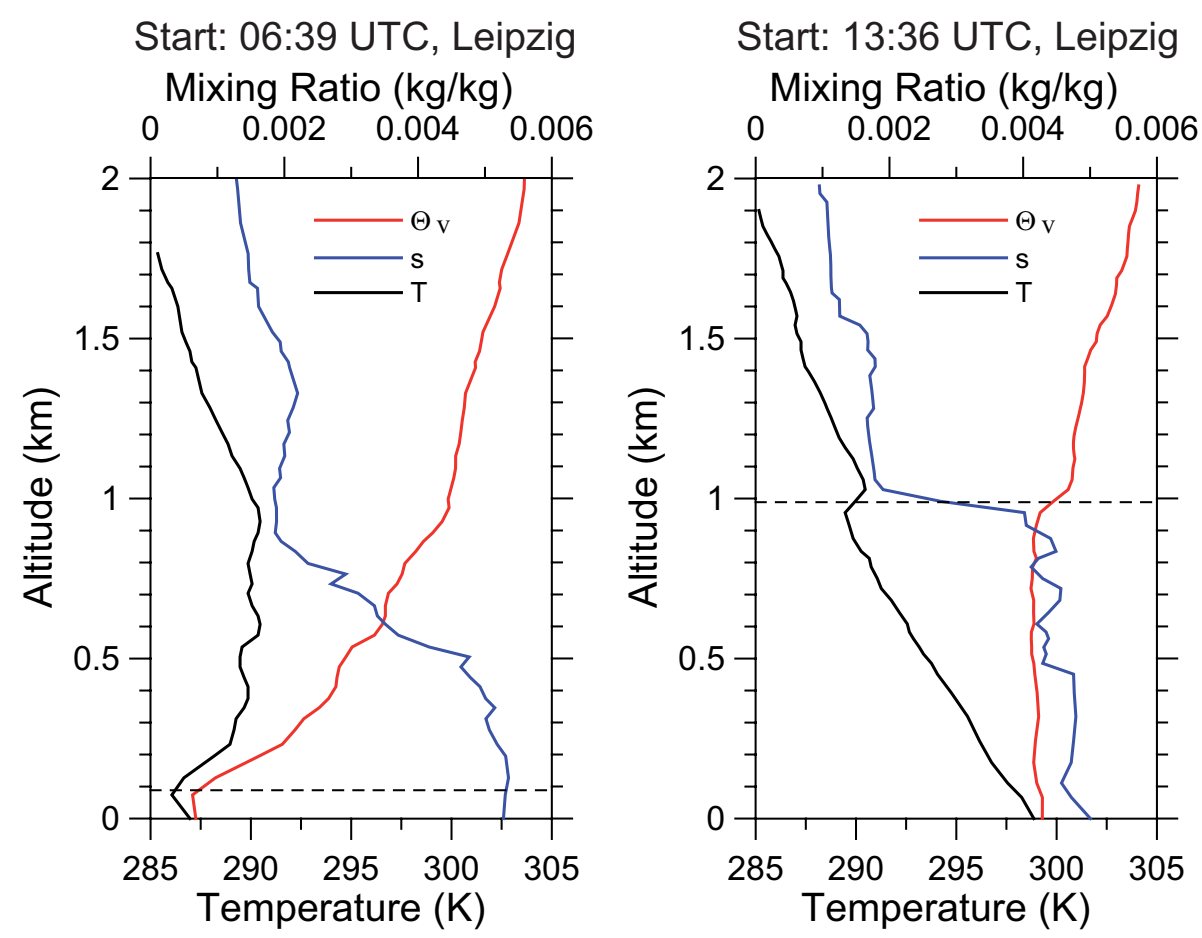

Fig. 8. Radiosonde profiles of virtual potential temperature (red), temperature (black), and water-vapor-to-dry-air mixing ratio (blue). The radiosondes were launched at the lidar site at 06:39 UTC (left, before the evolution of the BL), and 13:36 UTC (right, well-mixed BL). Dashed horizontal line shows the BL top height.

\section{Case studies}

Three measurement cases obtained at different aerosol and meteorological conditions are presented to discuss advantages and limits of the available lidar techniques. In addition to Polly, the wind Doppler lidar was operated continuously and several radiosondes were launched per day at the lidar site. The evolution of the BL in cloudless conditions is discussed first (11 September 2006). A case with complex aerosol layering (Saharan dust on top of the BL) observed on 13 September 2006 is presented next. In the third case (4 July 2006), cumulus convection complicated the BL top detection.

\section{$5.1 \quad 11$ September 2006}

Figure 7 (top) shows the BL evolution in terms of the range-corrected backscatter signal observed with Polly on 11 September 2006. Sunrise is at about 04:40 UTC, sunset at 17:35 UTC. A steady and almost constant growth of the BL depth is visible with a rate of $120 \mathrm{~m} / \mathrm{h}$ from 09:0014:00 UTC. The maximum depth of the BL of $1175 \mathrm{~m}$ is reached at 15:00 UTC.

In Fig. 7 (center), WiLi observations of vertical wind speed, and thus of the convective activity, are displayed. The convective period lasts from about 09:00 to almost 16:00 UTC. Vertical motion with upward velocities of up to
$2 \mathrm{~m} / \mathrm{s}$ and downward motion with up to $1.5 \mathrm{~m} / \mathrm{s}$ occurs. More details to the 11-13 September period in terms of aerosol, wind, and aerosol flux measurements are described by Engelmann et al. (2008). Simultaneous observations of a backscatter lidar and a wind lidar pointing to the zenith were first shown by Cohn and Angevine (2000).

Figure 8 presents radiosonde profiles of water-vapor mixing ratio $s$, temperature $T$, and virtual potential temperature $\Theta_{v}$. The first sonde was launched on 11 September 2006, 06:39 UTC and indicates a stable stratification of the atmosphere above $100 \mathrm{~m}$ height. The second sonde, launched at 13:36 UTC, shows a well-mixed BL with top height at $1 \mathrm{~km}$.

The results regarding the retrieval of BL top with the available four lidar methods and from the COSMO model (gradient-Richardson-number scheme) are shown in Fig. 7 (bottom). All lidar methods successfully determine the height of the BL top between 09:00 and 15:00 UTC. Before 09:00 and after 15:00 UTC the presence or the formation of the residual layer causes difficulties, especially in the case of the 5-min variance method. The signal averaging period of $5 \mathrm{~min}$ is too short so that the corresponding signal-to-noise ratio is too large for a proper determination of the BL top. The 5-min variance method is of relevance here, because it is one method to analyze the one-year POLLY data set which mostly consists of signal profiles measured within 5-min periods on a hourly basis. 


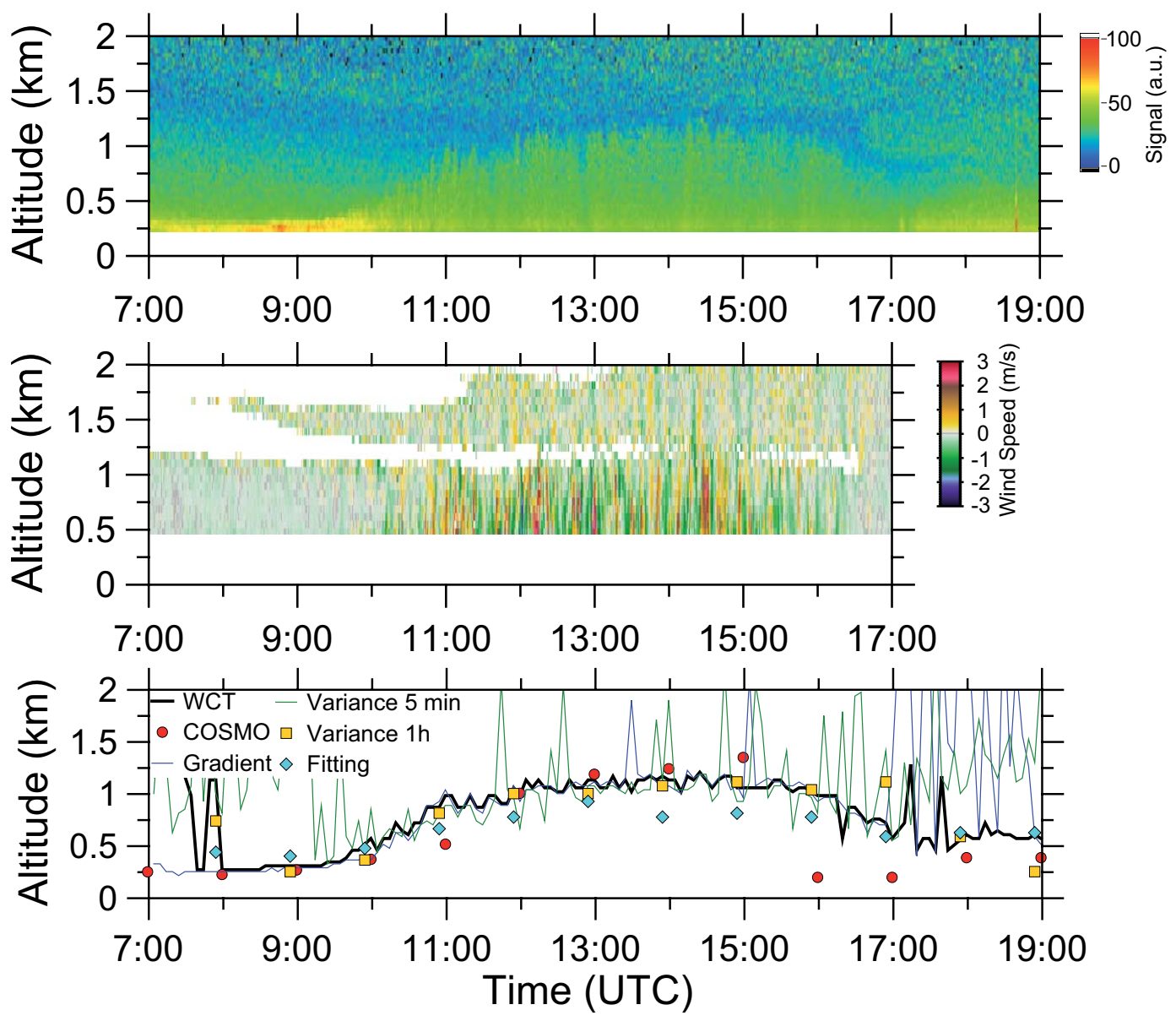

Fig. 9. Same as Fig. 7, except for 13 September 2006, 07:00-19:00 UTC (08:00-20:00 LT). Saharan dust is present above the cloudfree BL.

The COSMO model underestimates the BL top during the first period of the BL evolution (09:00-11:00 UTC), provides accurate results around noon and in the early afternoon for the fully developed BL, and also resolves the end of the convective period shortly before 16:00 UTC as indicated by the WiLi results in Fig 7b. After 18:00 UTC neither the model nor the lidar can provide reliable values of the nocturnal $\mathrm{BL}$ top. The output of COSMO is preset to $389 \mathrm{~m}$ at nighttime.

As mentioned in Sect. 3.1, the COSMO model is initialized at 00:00 and 12:00 UTC. BL top forecasts are shown for the periods from 01:00-11:00 UTC and 13:0023:00 UTC. Thus the model-derived BL top values presented for the morning hours (08:00-11:00 UTC) are comparably uncertain, and most accurate for the early-afternoon period (12:00-14:00 UTC).

The underestimation of the $\mathrm{BL}$ top by the COSMO model in the morning (09:00-11:00 UTC) may reflect that the critical-gradient-Richardson-number approach assumes steady state conditions (Zilitinkevich and Baklanov, 2002) as was mentioned in Sect. 3.2. This assumption is probably not fully valid during the period of strongest BL height increase.

\subsection{September 2006}

On 13 September 2006 a Saharan dust layer above the BL complicates the retrieval of the BL top. The lofted layer is best viewed in the WiLi plot (see Fig. 9, center). According to the vertical-wind data the convectively active period lasts from about 10:00 to about 15:30 UTC. Updraft velocities up to $2-3 \mathrm{~m} / \mathrm{s}$ and downdraft velocities of $1-2 \mathrm{~m} / \mathrm{s}$ are measured. The hourly growth rate of the BL depth is roughly $500 \mathrm{~m} / \mathrm{h}$ from 10:00-11:00 UTC.

Except the fitting method and the 5-min variance analysis, the other lidar retrieval techniques work well at these conditions of complex aerosol layering for the time period from 08:00-16:00 UTC. The fitting method has problems because a required clear signal step function at BL top is not given. Because the signal-to-noise ratio is low, the solutions of the 5 -min variance method show large fluctuations in the BL time series. Note, that the gradient method resolves the BL top at 07:00 and 08:00 UTC, but fails after 17:00 UTC. Similarly, the 1-h variance analysis produces uncertain results in the evening (17:00-19:00 UTC). Figure 9 is representative for a large fraction of analyzed cases of the 2006/2007 

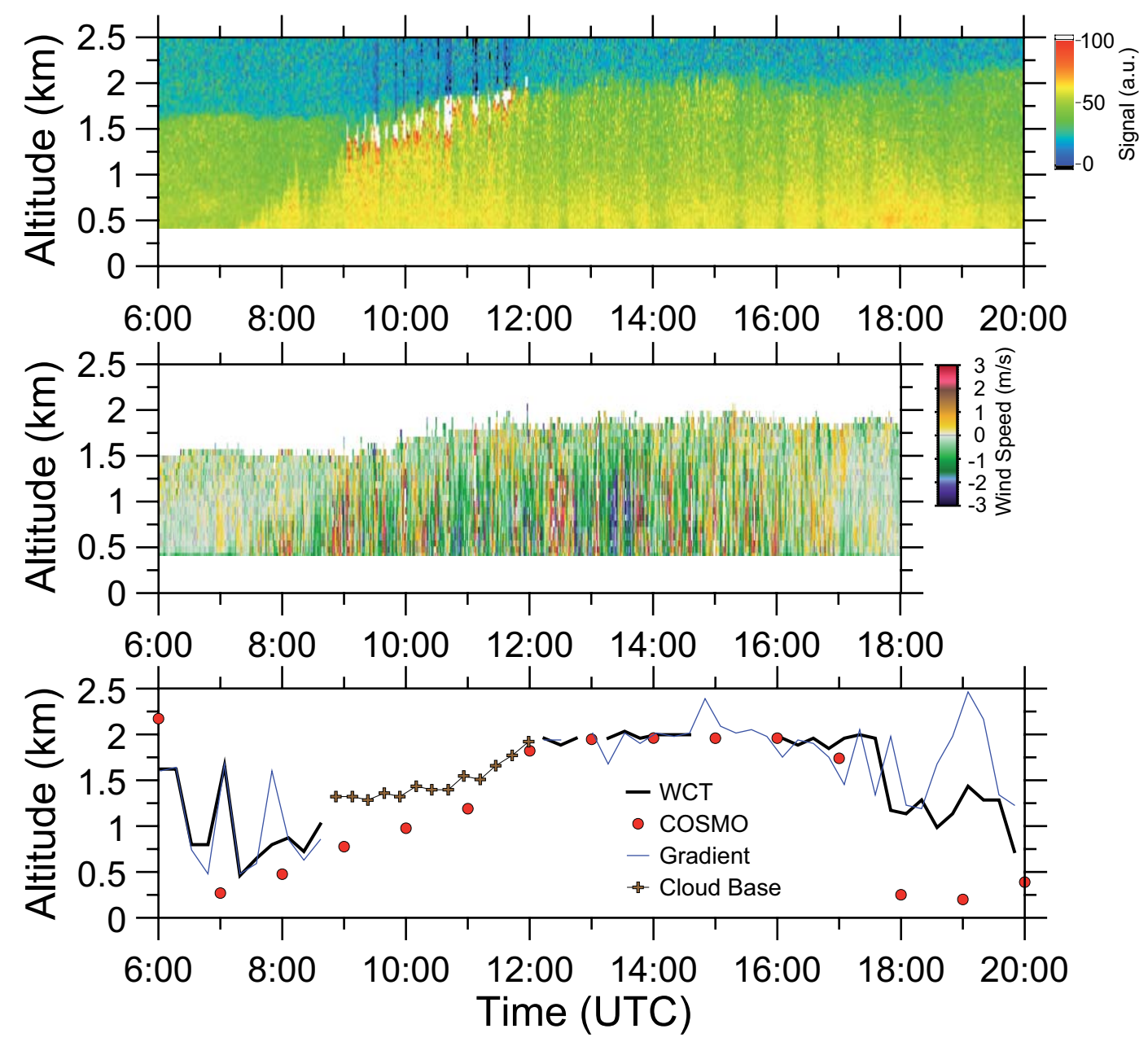

Fig. 10. Same as Fig. 7, except for 4 July 2006, 06:00-20:00 UTC (07:00-21:00 LT). Cumulus clouds develop between 09:00 and 12:00 UTC. Crosses (bottom plot) indicate cloud base.

data set. Mattis et al. (2008) show that in about 30\% out of all measurements performed in the framework of the EARLINET (European Aerosol Research Lidar Network) project lofted layers were present just above the boundary layer.

In Fig. 9, the COSMO model provides the most accurate solution at the initialization time of 12:00 UTC and in the early morning (07:00-09:00 UTC). The evolution of the BL top is clearly underestimated by the model at 11:00 UTC (11$\mathrm{h}$ forecast value) and overestimated at 15:00 UTC, possibly caused by the fact that the radiative impact of the Saharan dust layer is ignored in the simulations. The growth rate of the BL depth is $100 \mathrm{~m} / \mathrm{h}$ after the COSMO model for the period from 10:00-11:00 UTC instead of $500 \mathrm{~m} / \mathrm{h}$ as seen by the lidar. The model accurately predicts the end of the $\mathrm{BL}$ evolution close to 16:00 UTC which is in agreement with he Doppler lidar observations.

\subsection{July 2006}

A high-pressure system over eastern Europe and a lowpressure system over western Europe caused the advection of warm and humid air from southern Europe. In contrast to the cases discussed before, cumulus clouds formed at the top of the BL (see Fig. 10, top) in the morning of 4 July 2006. The BL reaches heights of about $2 \mathrm{~km}$ in the late afternoon. The BL top height increased by roughly $400 \mathrm{~m} / \mathrm{h}$ from $08: 00$ 11:00 UTC. The COSMO model predicts an hourly growth rate of about $250 \mathrm{~m} / \mathrm{h}$ for this time period.

The vertical-wind observations in Fig. 10 (center) indicate pronounced updrafts and downdrafts (up to $3 \mathrm{~m} / \mathrm{s}$ downward motion) during the daytime from 07:30 to almost 17:00 UTC (18:00 LT). Sunrise and sunset are 03:00 and 19:30 UTC in the beginning of July.

The BL-height time series obtained with the lidar WCT technique and the gradient method is compared to COSMO results in Fig. 10 (bottom). The Polly backscatter color plot 


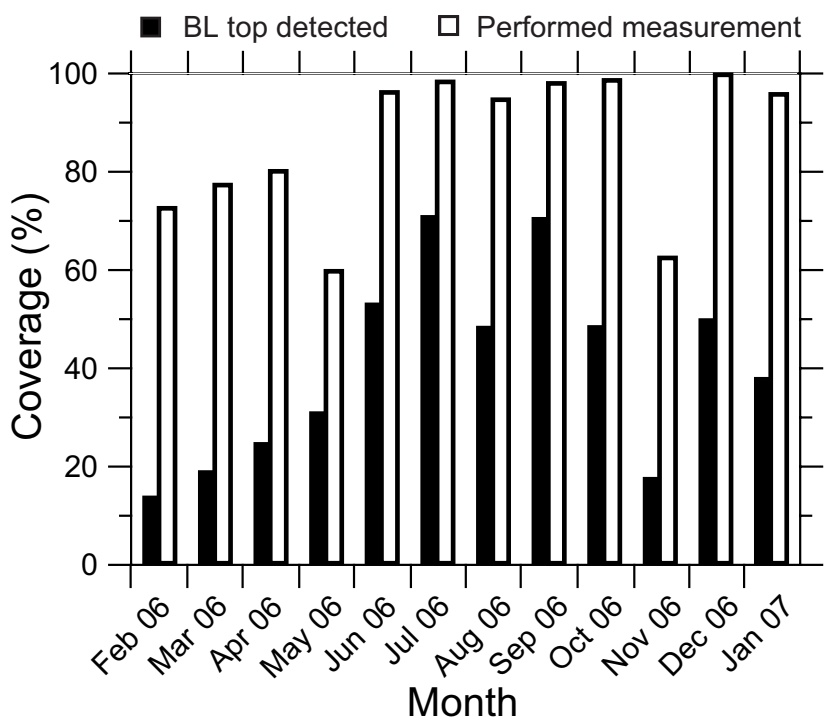

Fig. 11. Number of daytime lidar measurements (in percent, white columns) with respect to the theoretically possible number of daytime measurements $(100 \%$, from $4 \mathrm{~h}$ after sunsrise to $1 \mathrm{~h}$ before sunset) for each month from February 2006 to January 2007, and percentage of measurements for which the BL top could be determined (black columns).

indicates that the lidar detects the BL top even during the phase of cumulus convection. However, for clarity in the presentation, we omit BL-top solutions applied to cloudscreened lidar signals during the period when clouds developed. Cloud base is indicated by crosses in Fig. 10 (bottom). The vertical extension from base to top of the clouds varies from $200-400 \mathrm{~m}$. The BL top is thus roughly $100-200 \mathrm{~m}$ higher than cloud base (crosses).

Due to technical problems (periodic laser power variations after 12:00 UTC caused by air conditioning problems) several considerably corrupted 5-min signal average profiles exist around 13:00 UTC and from 14:45-16:00 UTC. During this times, the detection of the BL top partly fails with the gradient method whereas the modified WCT-method does not provide BL top values.

The COSMO model (6-11-h forecast data) obviously underestimates again the strength of the BL evolution. After re-initialization at 12:00 UTC, good agreement is found between lidar and model solutions. The model also predicts sufficiently well the time when the convective activity significantly weakens close to 17:00 UTC, as observed with the Doppler lidar WiLi.

\section{Statistical analysis (February 2006-January 2007)}

Continuous lidar observation as discussed in Sect. 5 were performed on less than $10 \%$ of the days in 2006 . The reg-

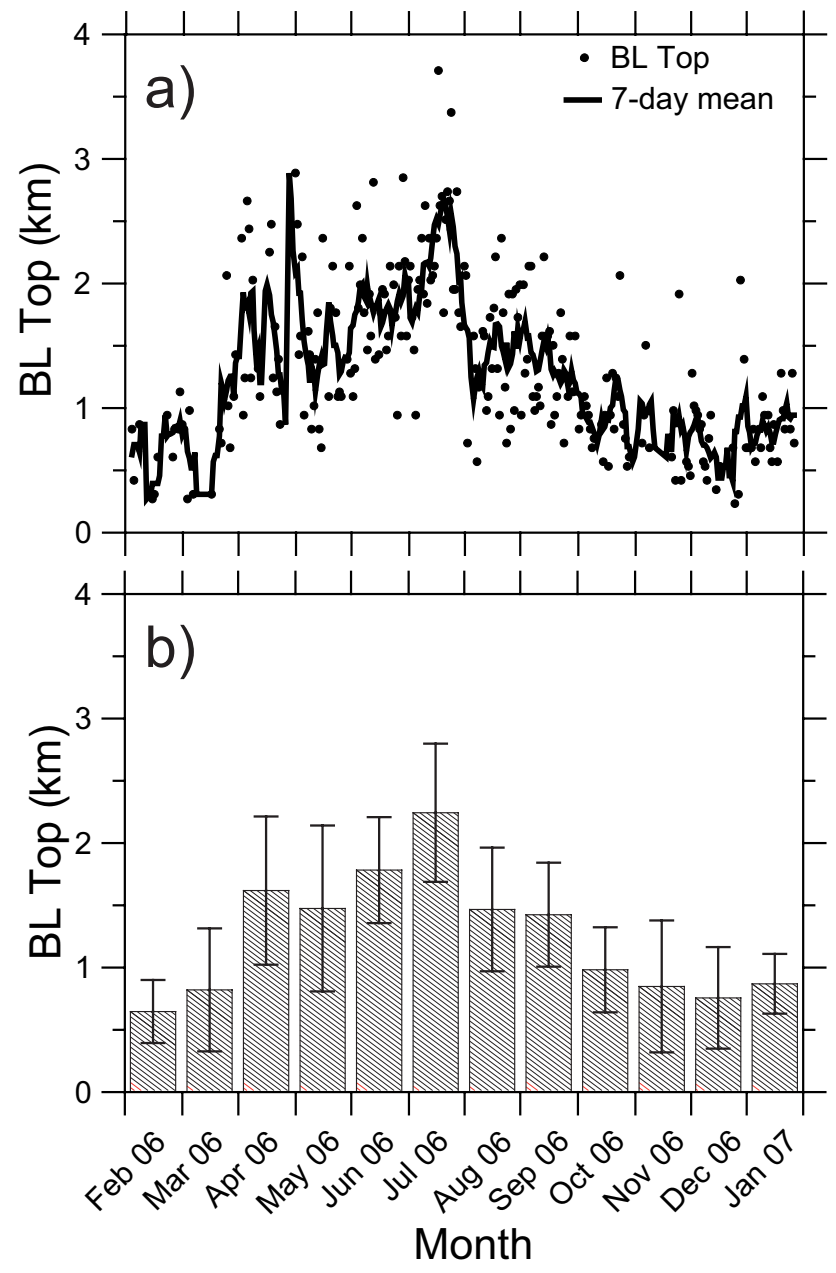

Fig. 12. (a) Daytime maximum BL top height determined with Polly from February 2006 to January 2007. Individual measurements (dots) and the 7-day running mean (solid line) are shown. (b) Corresponding monthly mean values and one-standard-deviation bars of the daytime maximum BL top height.

ular measurement program was described in Sect. 2. Signal profiles were measured with Polly from minute $8-13$ of each hour. The following statistical analysis is based on these fiveminute observations.

\subsection{BL top heights and growth rates}

Figure 11 gives an overview of the data coverage for each month. During 2310 out of the total of 2669 five-minute daytime periods (February 2006 to January 2007, $4 \mathrm{~h}$ after sunrise to $1 \mathrm{~h}$ before sunset) lidar measurements were possible. Data coverage is thus, on average, $87 \%$. In 1160 cases out of these 2310 five-minute observation periods the BL top height could successfully be determined with the automated WCT method. Low clouds, the lack of a significant decrease in the backscatter profile, or precipitation prohibited the BL depth determination in about $50 \%$ of the measurements. 


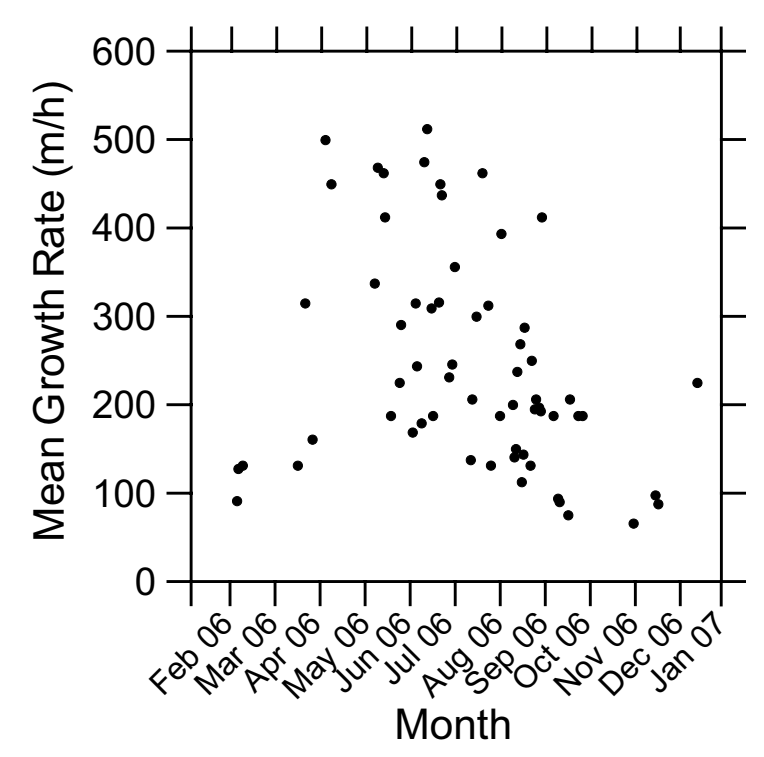

Fig. 13. Mean growth rate of the $B L$ depth during the main $B L$ built-up phase from about 08:00-09:00 to 11:00-14:00 UTC.

In the following we briefly summarize the main statistical findings. In Fig. 12a, the daily maximum BL depths are plotted together with a running one-week average. A clear seasonal cycle is found. Strong convective activity occurs from mid March to the end of September over Leipzig. Figure $12 \mathrm{~b}$ shows the corresponding monthly mean values and standard deviations of the daily maximum values. Whereas, in July 2006 the BL top in the early afternoon reached values of, on average, $2.2 \mathrm{~km}( \pm 0.7 \mathrm{~km})$ height, the monthly mean value of the afternoon BL top height did not exceed $700 \mathrm{~m}$ in February 2006. The seasonal mean of the daytime (08:0020:00 LT) maximum BL top is $1400 \mathrm{~m}$ in spring, $1800 \mathrm{~m}$ in summer, $1200 \mathrm{~m}$ in autumn, and $800 \mathrm{~m}$ in winter at the continental, central European site.

For 65 clear days (without fog, precipitation, and frontal passages combined with air mass change), the growth of the BL depth in the morning and early afternoon hours could be studied in detail. On all of these days, the minimum BL height (around 08:00 UTC) could be identified. Figure 13 shows the mean growth rate for the main period of the BL evolution. The main period is defined by the time when the BL depth begins to increase (e.g., 09:00 UTC) and the time when the BL top height reaches the $0.9 \mathrm{BL}$ daily maximum value (typically 11:00-14:00 UTC). As can be seen, mean growth rates from about $100-500 \mathrm{~m} / \mathrm{h}$ were observed. In cases with fast BL growth of 400-500 m the main phase of the evolution of the BL was two hours or even shorter. Large values of $400-500 \mathrm{~m} / \mathrm{h}$ are observed during the summer season (May to September).

Histograms of observed hourly and mean growth rates are shown in Fig. 14a and b, respectively. Most hourly growth
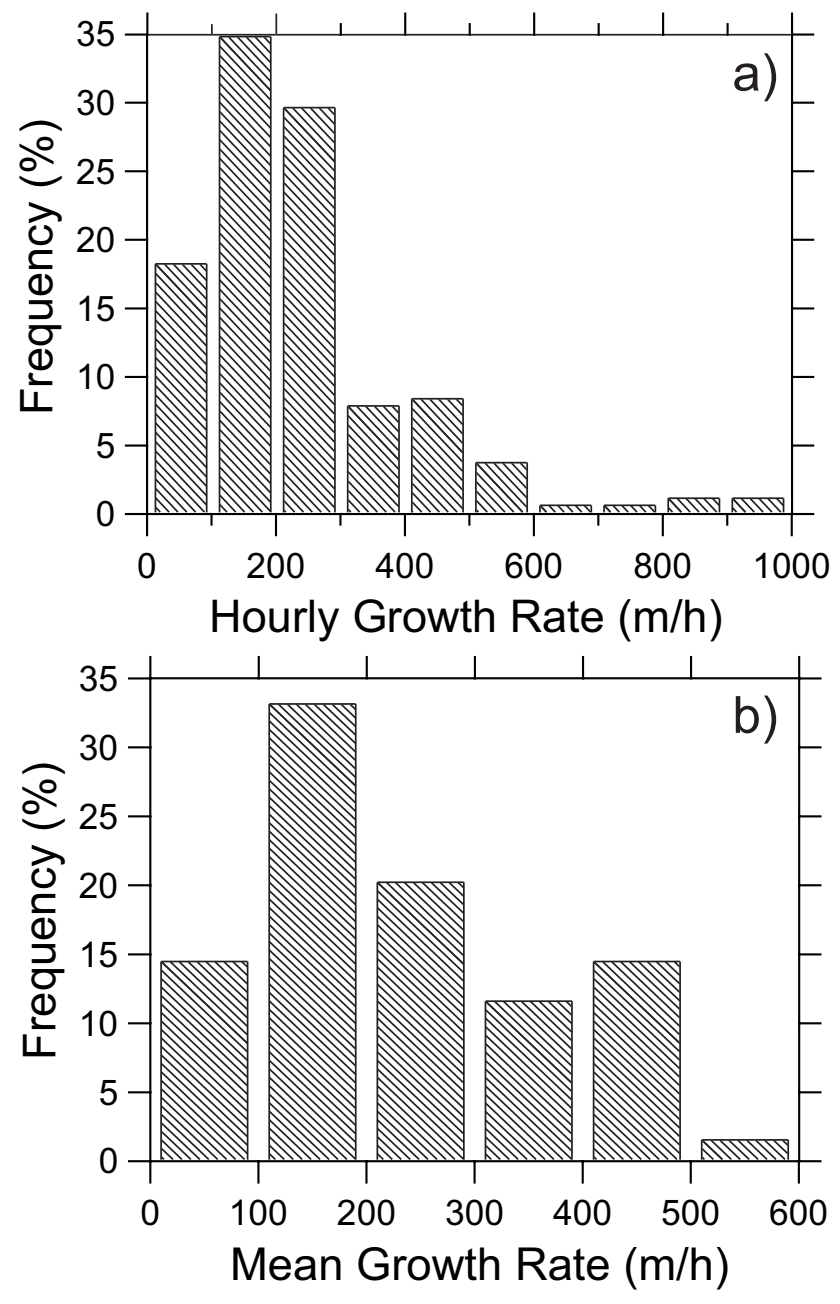

Fig. 14. Frequency distribution of (a) hourly and (b) mean BL growth rate (for the main growth period) as observed from February 2006 to January 2007.

rates as well as mean growth rates are found between 100 and $300 \mathrm{~m} / \mathrm{h}$ (about $65 \%$ ). The largest hourly growth rate of $940 \mathrm{~m} / \mathrm{h}$ was observed on 4 May 2006. The maximum mean growth rate of $510 \mathrm{~m} / \mathrm{h}$ was observed on 13 July 2006 .

\subsection{Comparison with COSMO-derived BL top heights}

In Fig. 15 hourly values of the BL top height and of the daily maximum BL top height determined from lidar data are compared with respective values obtained from the COSMO model outputs. Disregarding the large scatter in the data, a systematic underestimation of the daytime BL depth by the COSMO model is visible in both comparisons (on average almost 20\%). Strong deviations (COSMO BL depth $>2000 \mathrm{~m}$, lidar BL depth $<1000 \mathrm{~m}$ ) occurred in cases with clouds (not predicted by the COSMO model) or, vice versa, during cloud-free conditions (COSMO BL depth $<1000 \mathrm{~m}$, li- 
dar BL depth > 2000 m) when the COSMO model obviously predicted clouds and consequently a suppression of the BL evolution.

A case with a systematic underestimation of the BL top by COSMO is shown in Fig. 16. On average, the difference between the lidar and the COSMO BL height values is $270 \mathrm{~m}$ on this day. In contrast to the 4 July (Fig. 10), dry air was advected to eastern Germany on 3 July 2006 and the influence of a high pressure system over eastern Europe dominated. The mean growth rate of the BL top height was $150 \mathrm{~m} / \mathrm{h}$ between 08:00 and 12:00 UTC. The Doppler lidar measured partly vigorous upward and downward motions with extreme values close to $3 \mathrm{~m} / \mathrm{s}$ between 10:30 and 17:00 UTC.

The systematic underestimation of the BL evolution by the COSMO model is most probably caused by an overestimation of the high pressure influence (large scale subsidence of air) for the Leipzig grid point. A clear reason for the systematic deviation can however not be given because of the complex parameterization of turbulence and soil characteristics in the COSMO model. The forecast model predicts a weakening of the convective activity as early as 15:00-16:00 UTC, whereas the Doppler lidar (center plot in Fig. 16) observed a strong updraft after 16:00 UTC and the end of the convectively active phase not before 17:00 UTC. Possible reasons for the observed underestimation and how this problem can be overcome are discussed by Steeneveld et al. (2007).

The comparison of the daily mean growth rates obtained from Polly and COSMO model data for the 65 chosen days is shown in Fig. 17. A reasonable agreement is observed up to values of about $300 \mathrm{~m} / \mathrm{h}$. The corresponding linear regression line for values below $300 \mathrm{~m} / \mathrm{h}$ is shown. According to this fit, an underestimation of the mean BL growth rate by about $25 \%$ by the COSMO model is found.

\section{Conclusions}

Lidar is a well-established technique for continuous vertical profiling of aerosols throughout the troposphere. Here, we have shown (and confirmed previous work in this field) that lidar is also a useful and reliable tool for a continuous and precise monitoring of the daytime development of the $\mathrm{BL}$ depth. We selected the WCT method for an automated BL top detection. To guarantee a robust data analysis, we introduced some modifications (thresholds to clearly identify BL top as well as clouds, use of a height-dependent dilation).

The statistical analysis of the one-year data set revealed that the seasonal mean of the daytime (about 08:0020:00 LT) maximum BL top is $1400 \mathrm{~m}$ in spring, $1800 \mathrm{~m}$ in summer, $1200 \mathrm{~m}$ in autumn, and $800 \mathrm{~m}$ in winter at the continental, central European lidar site. BL top typically increases by $100-500 \mathrm{~m}$ per hour in the morning of convective days. Mean growth rates were found most frequently between 100 and $300 \mathrm{~m} / \mathrm{h}$.
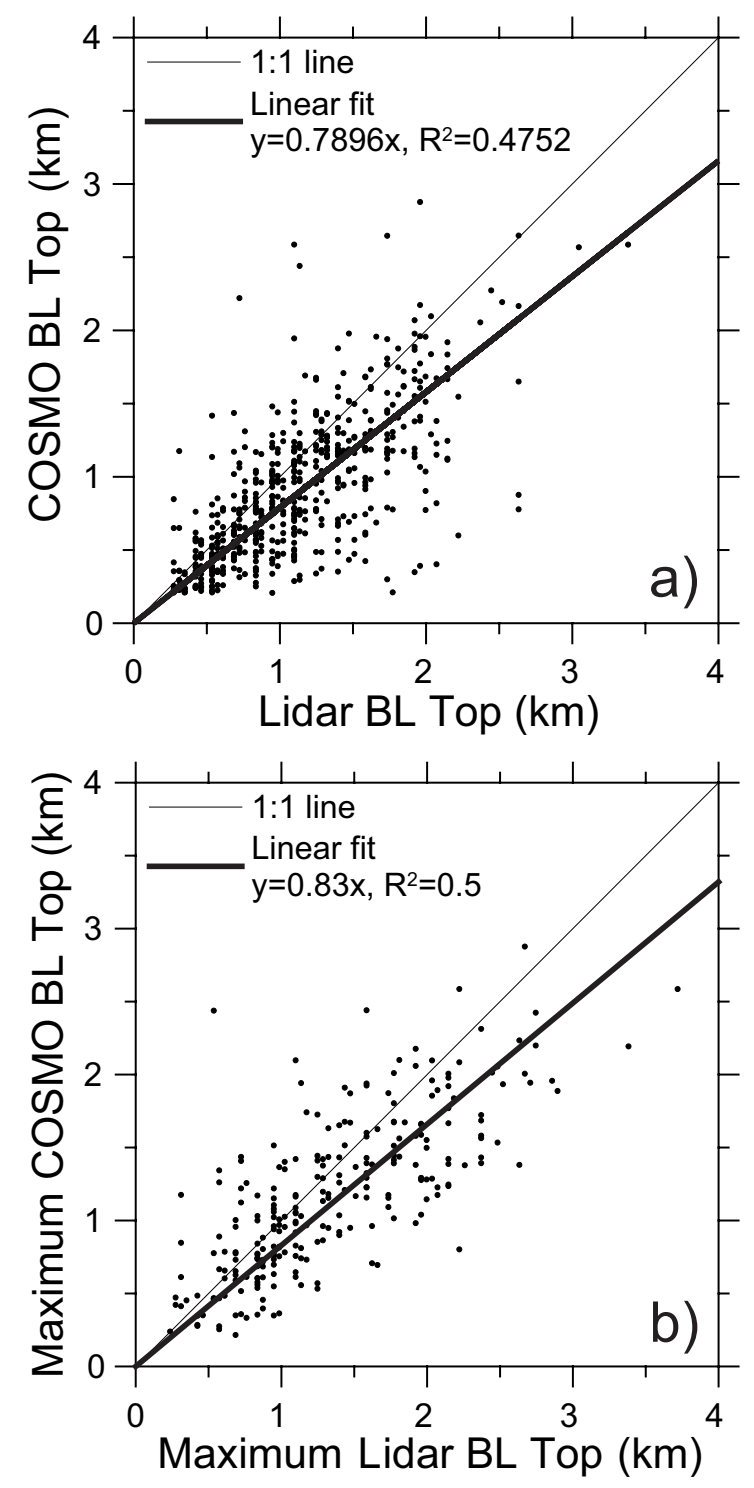

Fig. 15. Comparison of BL top heights as derived from lidar observations and COSMO model data, (a) hourly values between 10:00 and 14:00 UTC, (b) daily maximum BL top heights. Linear regression lines are shown in addition.

The comparison with COSMO model results showed that the forecast model underestimated the BL top height by, on average, roughly $20 \%$ and the evolution of the BL (mean growth rate) by about $25 \%$. Strongest deviations occur when clouds are predicted, but not present and vice versa. 

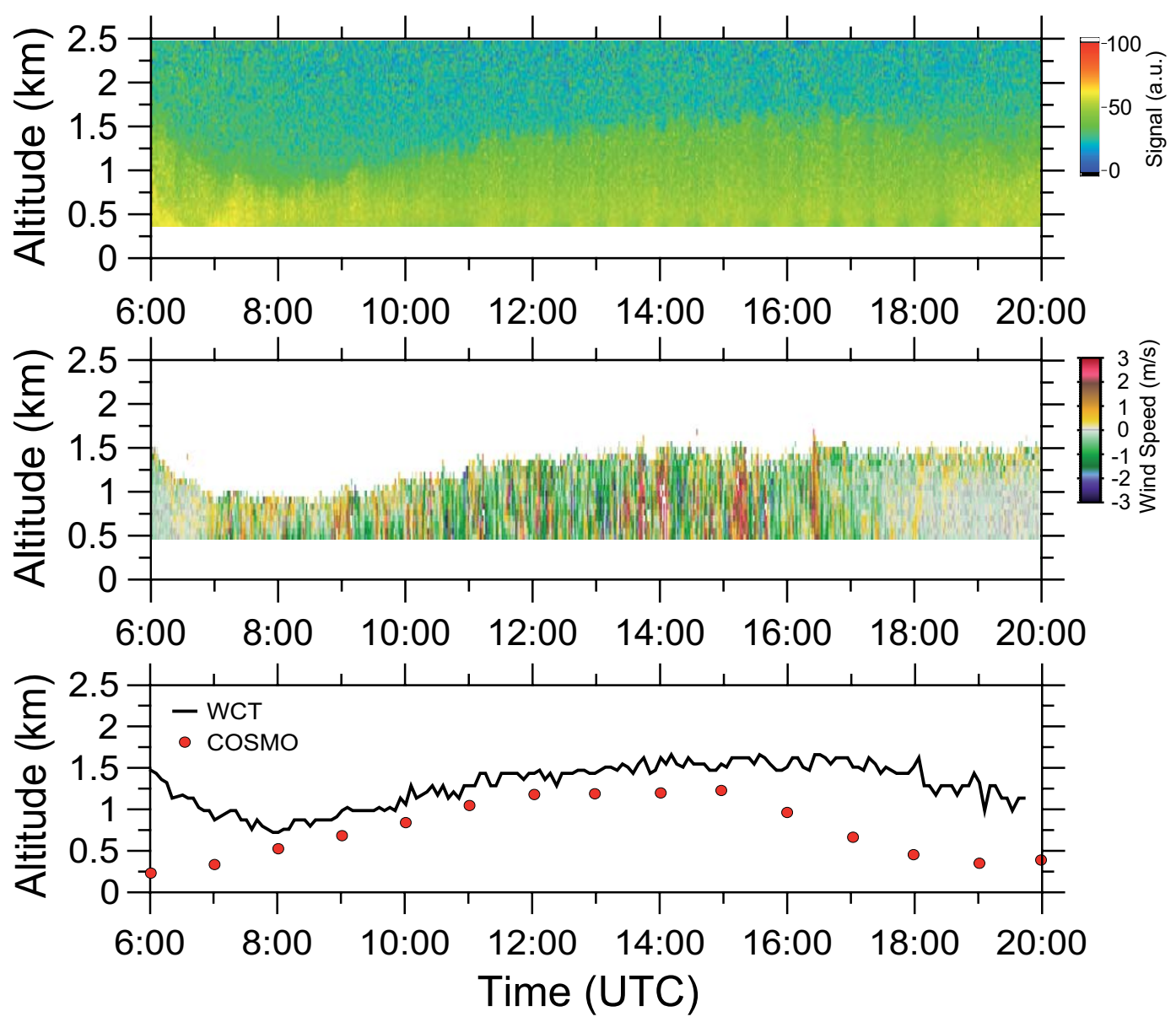

Fig. 16. Same as Fig. 10, except for the cloudfree 3 July 2006, 06:00-20:00 UTC (07:00-21:00 LT).

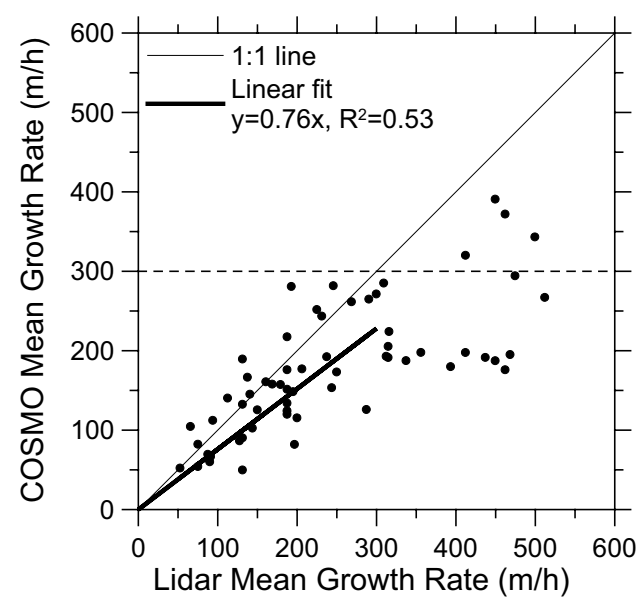

Fig. 17. Comparison of mean BL growth rates as derived from lidar observations and COSMO model data. The shown linear regression line considers values up to $300 \mathrm{~m} / \mathrm{h}$ only.
Acknowledgement. We are grateful to the German Meteorological Service for providing the COSMO model data used in our study. We thank Barbara Fay for providing all the information about the COSMO model we required and for answering all of our numerous questions.

Edited by: G. Vaughan

\section{References}

Althausen, D., Engelmann, R., Foster, R., Rhone, P., and Baars, H.: Portable Raman lidar for determination of particle backscatter and extinction coefficients, in: Reviewed and revised papers presented at the 22nd ILRC, ESA SP-561, Volume 1, edited by: Pappalardo, G. and Amodeo, A., 83-86, ESA Publications Division, ESTEC, Noordwijk, The Netherlands, 2004.

Althausen, D., Engelmann, R., Baars, H., Heese, B., and Komppula, M.: Portable Raman lidar Polly XT for automatic profile measurements of aerosol backscatter and extinction coefficient, in: Proceedings, 24th ILRC, edited by: Hardesty, M. and Mayor, S., 45-48, NCAR, Boulder, CO, 2008. 
Ansmann, A. and Müller, D.: Lidar - Range-Resolved Optical Remote Sensing of the Atmosphere, chap. Lidar and atmospheric aerosol particles, Springer, New York, 2005.

Ansmann, A., Wandinger, U., Riebesell, M., Weitkamp, C., and Michaelis, W.: Independent measurement of extinction and backscatter profiles in cirrus clouds by using a combined Raman elastic-backscatter lidar, Appl. Opt., 31, 7113-7131, 1992.

Ansmann, A., Engelmann, R., Althausen, D., Wandinger, U., Hu, M., Zhang, Y., and He, Q.: High aerosol load over the Pearl River Delta, South China, observed with Raman lidar and Sun photometer, Geophys. Res. Lett., 32, L13815, doi:10.1029/2005GL023094, 2005.

Beyrich, F.: Mixing height estimation from sodar data - a critcal discussion, Atmos. Environ., 31, 3941-3953, 1997.

Brooks, I.: Finding Boundary Layer Top: Application of a wavelet covariance transform to lidar backscatter profiles, J. Atmos. Ocean. Tech., 20, 1092-1105, 2003.

Campbell, J. R., Hlavka, D. L., Welton, E. J., Flynn, C. J., Turner, D. D., Spinhirne, J. D., Scott, V. S., and Hwang, I. H.: Full-time, eye-safe cloud and aerosol lidar observations at Atmospheric Radiation Measurement program sites: instruments and data processing., J. Atmos. Ocean. Tech., 19, 431-442, 2002.

Cohn, S. A. and Angevine, W. M.: Boundary layer height and entrainment zone thickness measured by lidars and wind-profiling radars, J. Appl. Meteorol., 39, 1233-1247, 2000.

Emeis, S., Münkel, C., Vogt, S., Müller, W., and Schäfer, K.: Atmospheric boundary-layer structure from simultaneous SODAR, RASS, and ceilometer measurements, Atmos. Environ., 38, 273286, 2004.

Engelmann, R., Wandinger, U., Ansmann, A., Müller, D., Zeromskis, E., Althausen, D., and Wehner, B.: Lidar observations of the vertical aerosol flux in the planetary boundary layer, J. Atmos. Ocean. Tech., 25, 1296-1306, 2008.

Fay, B.: Evaluation and intercomparison of mixing heights derived from a Richardson number scheme and other $\mathrm{MH}$ formulae using operational NWP models at the German Weather Service, in: 5th International Conference on Harmonisation within Atmospheric Dispersion Modelling, Rhodes, 18-21 May 1998.

Fay, B. and Neunhäuserer, L.: Evaluation of high-resolution forecasts with the non-hydrostaticnumerical weather prediction model Lokalmodell for urban air pollution episodes in Helsinki, Oslo and Valencia, Atmos. Chem. Phys., 6, 2107-2128, 2006, http://www.atmos-chem-phys.net/6/2107/2006/.

Fay, B., Schrodin, R., Jacobsen, I., and Engelbart, D.: Validation of mixing heights derived from the operational NWP models at the German Weather Service, in: The Determination of the Mixing Height - Current Progress and Problems, EURASAP Workshop Proceedings, 1-3 October 1997, Ris $\varnothing$ National Laboratory, edited by: Gryning, S., Beyrich, F., and Batchvarova, E., 55-58, 1997.

Flamant, C., Pelon, J., Flamant, P., and Durand, P.: Lidar determination of the entrainment zone thickness at the top of the unstable marine atmospheric boundary layer, Bound.-Lay. Meteorol., 83, 247-284, 1997.

Hooper, W. P. and Eloranta, E. W.: Lidar measurements of wind in the planetary boundary layer: the method, accuracy, and results from joint measurements with radiosonde and kytoon, J. Clim. Appl. Meteorol., 25, 990-1001, 1986.

Lammert, A. and Bösenberg, J.: Determination of the convective boundary-layer height with laser remote sensing, Bound.-Lay. Meteorol., 119, 157-170, 2005.

Liu, Z., Vaughan, M. A., Winker, D. M., Hostetler, C. A., Poole, L. R., Hlavka, D., Hart, W., and McGill, M.: Use of probability distribution functions for discriminating between cloud and aerosol in lidar backscatter data, J. Geophys. Res., 109, D15202, doi:10.1029/2004JD004732, 2004

Martucci, G., Matthey, R., Mitev, V., and Richner, H.: Comparison between backscatter lidar and radiosonde measurements of the diurnal and nocturnal stratification in the lower troposphere, $\mathrm{J}$. Atmos. Ocean. Tech., 24, 1231-1244, 2007.

Mattis, I., Müller, D., Ansmann, A., Wandinger, U., Preißler, J., Seifert, P., and Tesche, M.: Ten years of multiwavelength Raman lidar observations of free-tropospheric aerosol layers over central Europe: Geometrical properties and annual cycle, J. Geophys. Res., 113, D20202 doi:10.1029/2007JD009636, 2008.

Menut, L., Flamant, C., Pelon, J., and Flamant, P. H.: Urban boundary-layer height determination from lidar measurements over the Paris area, Appl. Opt., 38, 945-954, 1999.

Morille, Y., Haeffelin, M., Drobinski, P., and Pelon, J.: STRAT: an automated algorithm to retrieve the vertical structure of the atmosphere from single-channel lidar data, J. Atmos. Ocean. Tech., 24, 761-775, 2007

Müller, D., Tesche, M., Eichler, H., Engelmann, R., Althausen, D., Ansmann, A., Cheng, Y. F., Zhang, Y., and Hu, M.: Strong particle absorption over the Pearl River Delta (south China) and Beijing (north China) determined from combined Raman lidar and Sun photometer observations, Geophys. Res. Lett., 33, L20811, doi:10.1029/2006GL027196, 2006.

Müller, D., Ansmann, A., Mattis, I., Tesche, M., Wandinger, U., Althausen, D., and Pisani, G.: Aerosol-type-dependent lidar-ratios observed with Raman lidar, J. Geophys. Res., 112, D16202, doi:10.1029/2006JD008292, 2007

Piironen, A. K. and Eloranta, E. W.: Convective boundary layer depths and cloud geometrical properties obtained from volume imaging lidar data, J. Geophys. Res., 100, 569-576, 1995.

Russel, P., Uthe, E., Ludwig, F., and Shaw, N.: A comparison of atmospheric structure as observed with monostatic acoustic sounder and lidar techniques, J. Geophys. Res., 79, 5555-5566, 1974.

Seibert, P., Beyrich, F., Gryning, S.-E., Joffre, S., Rassmussen, A., and Tercier, P.: Review and intercomparison of operational methods for the determination of the mixing height, Atmos. Environ., 34, 1001-1027, 2000.

Steeneveld, G. J., van de Wiel, B. J., and Holtslag, A. A. M.: Diagnostic equations for the stable boundary layer height: evaluation and dimensional analysis, J. Appl. Meteorol. Clim., 46, 212-225, 2007.

Steyn, D., Baldi, M., and Hoff, R. M.: The detection of mixed layer depth and entrainment zone thickness from lidar backscatter profiles, J. Atmos. Ocean. Tech., 16, 953-959, 1999.

Stull, R. B.: An Introduction to Boundary Layer Meteorology, Kluwer Academic Publishers, Dordrecht/Boston/London, 1988.

Tesche, M., Ansmann, A., Müller, D., Althausen, D., Engelmann, R., Hu, M., and Zhang, Y.: Particle backscatter, extinction, and lidar ratio profiling with Raman lidar in south and north China, Appl. Opt., 46, 6302-6308, 2007.

Turner, D. D., Ferrare, R. A., Heilman Brasseur, L. A., Feltz, W. F., and Tooman, T. P.: Automated retrievals of water vapor 
and aerosol profiles from an operational Raman lidar, J. Atmos. Ocean. Technol., 19, 37-50, 2002.

Vogelezang, D. H. P. and Holtslag, A. A. M.: Evaluation and model impacts of alternative boundary-layer height formulations, Bound.-Lay. Meteorol., 81, 245-269, 1996.

Wandinger, U. and Ansmann, A.: Experimental determination of the lidar overlap profile with Raman lidar, Appl. Opt., 41, 511514, 2002.

Wiegner, M., Emeis, S., Freudenthaler, V., Heese, B., Junkermann, W., Münkel, C., Schäfer, K., Seefeldner, M., and Vogt, S.: Mixing layer height over Munich, Germany: variability and comparisions of different methodologies, J. Geophys. Res., 111, D13201, doi:10.1029/2005JD006593, 2006.
Zeromskis, E., Wandinger, U., Althausen, D., Engelmann, R., Rhone, P., and Foster, R.: Coherent Doppler lidar for wind profiling in the lower atmosphere, in: Extended Abstracts, Sixth International Symposium on Tropospheric Profiling: Needs and Technologies, edited by: Wandinger, U., 71-73, Leibniz Institute for Tropospheric Research, Leipzig, Germany, 2003.

Zilitinkevich, S. and Baklanov, A.: Calculation of the height of the stable boundary layer in practical applications, Bound.-Lay. Meteorol., 105, 389-409, 2002. 